\title{
UNIVERSITYOF
}

FORWARD

THINKING

WESTMINSTER用

WestminsterResearch

http://www.westminster.ac.uk/westminsterresearch

\section{Data Visualisation Does Political Things}

Boehnert, J.

This is an electronic version of a paper presented at DRS2016: Design + Research + Society: Future-Focused Thinking, University of Brighton 27-30 June 2016.

(c) The Author, 2016.

The WestminsterResearch online digital archive at the University of Westminster aims to make the research output of the University available to a wider audience. Copyright and Moral Rights remain with the authors and/or copyright owners.

Whilst further distribution of specific materials from within this archive is forbidden, you may freely distribute the URL of WestminsterResearch: ((http://westminsterresearch.wmin.ac.uk/)).

In case of abuse or copyright appearing without permission e-mail repository@westminster.ac.uk 


\title{
Future-Focused Thinking
}

\section{Data Visualisation Does Political Things}

\author{
Dr. Joanna Boehnert ${ }^{\text {a }}$ \\ ${ }^{a}$ CREAM, University of Westminster, UK \\ *j.boehnert@westminster.ac.uk
}

\begin{abstract}
In this paper I advance the theory of critical communication design by exploring the politics of data, information and knowledge visualisation in three bodies of work. Data reflects power relations, special interests and ideologies that determine which data is collected, what data is used and how it is used. In a review of Max Roser's Our World in Data, I develop the concepts of digital positivism, datawash and darkdata. Looking at the Climaps by Emaps project, I describe how knowledge visualisation can support integrated learning on complex problems and nurture relational perception. Finally, I present my own Mapping Climate Communication project and explain how I used discourse mapping to develop the concept of discursive confusion and illustrate contradictions in this politicised area. Critical approaches to information visualisation reject reductive methods in favour of more nuanced ways of presenting information that acknowledge complexity and the political dimension on issues of controversy.
\end{abstract}

Keywords: data visualisation; controversy mapping; datawash; discourse mapping

\section{Introduction}

Data visualisation makes big data and other information accessible and meaningful in ways that reflect both the explicit intentions and the implicit assumptions of designers. Despite efforts some designers make to be neutral and objective interpreters, all information design is embedded with suppositions. When data visualisation illustrates trends and presents truth claims it privileges certain perspectives. We all rely on accurate information that effectively captures the complexity of contemporary conditions but neither data itself nor data visualisations are politically neutral. Data reflects power relations, special interests and ideologies in terms of which data is collected, what data is used and how it is used. In this paper I will advance critically informed approaches to data visualisation. Due to the inherent reductionism in data visualisation it can easily be used in ways that obscure complex phenomenon. For this reason, in many instances knowledge visualisation is a more effective and honest approach. This is especially true on issues of controversy. 
I explore these ideas by examining the politics of data, information and knowledge visualisations in three bodies of work. Firstly Max Roser's Our World in Data project presents charts of economic, social and ecological phenomenon. Reviewing this work I develop the concepts of digital positivism, datawash and darkdata. Next, Climaps by Emaps elegantly captures the complexity of climate debates. With this work I describe and develop the concepts of knowledge visualisation and relational perception. Finally I present my own Mapping Climate Communication research. This work uses of systems and discourse mapping to capture controversy in this politicised area. The three sets of work display highly reductive methods (Roser) and then more nuanced and critically aware ways of presenting information that acknowledge the political dimension on issues of controversy.

\section{Theorising Critical Data Visualisation}

In order to understand how meaning is constructed with data visualisation and what can go wrong, it helps to theorise the various practices involved. Communication design selects and orders information. Visualisations are interpretations that can only capture partial information. Data visualisation is created in a process involving multiple decisions. The decisions involving which data to collect, which data to illustrate, how to illustrate it and where to illustrate it are decisions that reflect assumptions, unstated (often unacknowledged) ideological perspectives and subjective judgments. With these choices, some information will always be missing. Catherine D'Ignazio claims that

"Even when we rationally know that data visualizations do not represent 'the whole world', we forget that fact and accept charts as facts because they are generalized, scientific and seem to present an expert, neutral point of view" (2015, para.1).

For this reason data visualisation must be understood as "one more powerful and flawed tool of oppression" (D'Ignazio 2015, para. 2). Data visualisation reveals certain phenomenon while simultaneously concealing more complicated realities. In a world with dramatic power imbalances, some people's interests are represented at the expense of others.

Within data visualisation meaning is constructed by both the designer and the audience. Cultural theorist and sociologist Stuart Hall (1973) describes how communication is encoded by a producer and then decoded by an audience in ways that are processes of cultural translation. In both instances, interpretations occurs. Designers construct data visualisation by selecting relevant datasets and organising data to tell a particular story and to reveal certain elements about a situation. Audiences decode data visualisation by interpreting the visual strategies and codes according to cultural conventions and their own assumptions. Approaching data visualisation critically involves recognising which story is being told and also anticipating what stories are not told about the same situation. Why are some perspectives communicated while others are not? Furthermore, it is necessary to 
consider how narrative, style and approach reflects on the content. The methods used to communicate content matter in subtle ways that are not always clear.

Data visualisation often uses information encoded with numbers. Numerical data is an abstract type of information captured with quantitative values. Identified elements are counted with others of the same type in order to facilitate comparison with quantities of different types. While this type of quantitative reasoning has obvious virtues, its hegemony has dramatic consequences in the manner that the society is organised. Sociologist Boaventura de Sousa Santos explains:

"To know means to quantify. Scientific rigour is gauged by the rigour measurement. The intrinsic qualities of the object, so to speak, do not count, and are replaced by quantities that can be translated. Whatever is not quantifiable is scientifically irrelevant...[thus] the scientific method is based on the reduction of complexity" (2007, p.18).

This reliance on quantitative reasoning flattens out all phenomena to what can be captured by numbers. By reducing observable facts to numbers the "act of measurement loses more information than it gains" (Wheatley 2006, p.65). Purely quantitative approaches to information design often fail to capture power relations, ideologies, attitudes, motivations and behaviours that cannot be reduced to a number.

For these reasons, data visualisation that is purely quantitative and numerical is often reductionist and over-simplistic. Clearly empirical and quantitative methods are a necessary foundation for analysis in many instances - but these modes of analysis are not the only way of knowing relevant to complex and controversial problems. The dominance and over-reliance on empirical and quantitative reasoning is problematic. Qualitative and critical approaches often offer more nuanced understanding of the full set of relationships within phenomena under investigation.

Digital methods and numerical data can give data visualisation an unwarranted veneer of objectivity and legitimacy. Communication theorists Vincent Mosco (2014) and Christian Fuchs (2015) describe how digital positivism advances a false certainty and an over-simplistic understanding of how data mediates knowledge. Digital positivism refers to the ways that digital methods can assume an authority associated with empirical work and the hard sciences. Digital positivism prioritizes "quantitative over qualitative data, arguing that the former provides the best opportunity for meaningful generalizations and that, when necessary, qualitative states can be rendered qualitatively" (Mosco 2014, p.196). The danger here is not only that complexity is reduced to numbers, but that the certain types of knowledge are prioritised as the expense of others. This reductive approach results in distorted meanings.

"It is uncertain what is worse: that big data treats problems thorough oversimplication or that it ignores those that require a careful treatment of subjectivity, including lengthy observation, depth interviews, and appreciation for the social production of meaning." (Ibid., p.198). 
Data visualisation is all too often made with a digital positivist approach. Pretenses to objectivity with numerical data can be deceptive. Digital positivism fosters a false sense of epistemic certainty that can be a risky on issues of the environment, technology and science; and unethical on issues of justice. Data displays embody values, perspectives, ideologies and political propositions that are obscured by the authority of digital positivism. David Brookes explains that

\footnotetext{
"data is never raw; it's always structured according to somebody's predispositions and values. The end result looks disinterested, but, in reality, there are value choices all the way through, from construction to interpretation... This is not to argue that big data isn't a great tool. It's just that, like any tool, it's good at some things and not at others." (2013, para. 14).
}

The data visualisations described below are examples the dangers of digital positivism. They demonstrate why data visualisation must be approached critically.

\section{Our World In Data}

Our World in Data is a research project conducted by economist Max Roser at the Institute for New Economic Thinking at the Oxford Martin School. The project offers overviews of global trends with dozens of charts and data visualisations on a wide variety of topics posted on the project website. The website claims it is "visualising the empirical evidence" and the headline over many charts reads: "an empirical view". On May 10 2015 Max Roser tweeted "Declining Racial Violence in the US since 1882" (@MaxCRoser) and embedded a line chart in the tweet displaying decreasing numbers of lynching in the United States over the past century (figure 1). On Roser's website there is a detailed bar chart on the number of lynchings (figure 2 ). These charts are not a reliable summary of racial violence in the USA. Roser has cherry picked particular datasets and then made a sweeping claim about racial violence in America. By visualising antiquated data while ignoring more relevant data (such as police killings of black people) these charts bolster a political perspective and serve a particular narrative.

Activists mobilising to highlight police violence towards black and brown people claim that racial killings have been systematically dismissed in the American justice system. The FBI admits that it does not collect complete information on USA law enforcement police killings and so these statistics are only collected by newspapers and activists organisations (Swaine \& Laughland 2015). Decisions with political implications have been made at all stages: the necessary data is not counted by official bodies, the choice to use the lynching data to make charts, the choice to label the chart as representative of racial violence, etc. 
Max Roser @MaxCRoser · May 10

Declining Racial Violence in the US since 1882

From: OurWorldlnData.org/data/violence-...

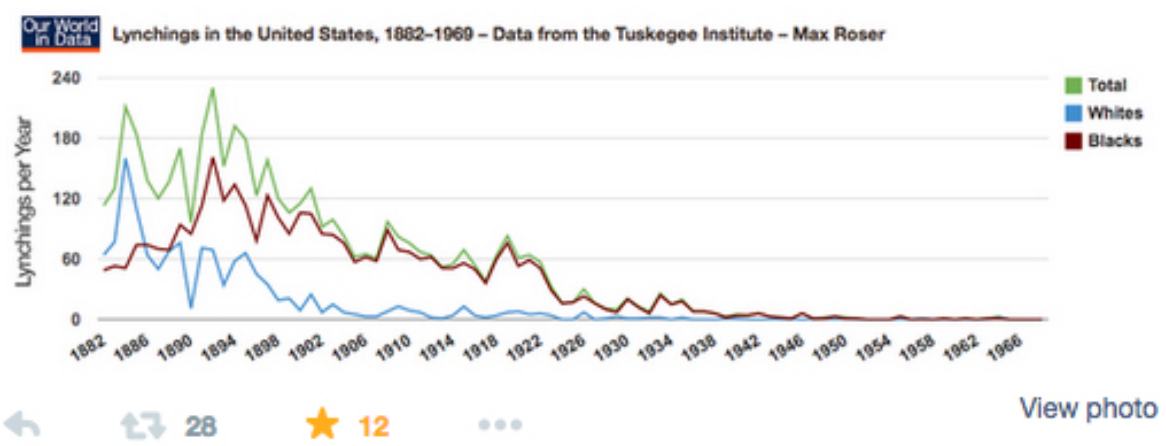

Figure 1 'Declining Racial Violence', Tweet by Max Roser, 10 May 2015 with embedded line chart.

Empirical View

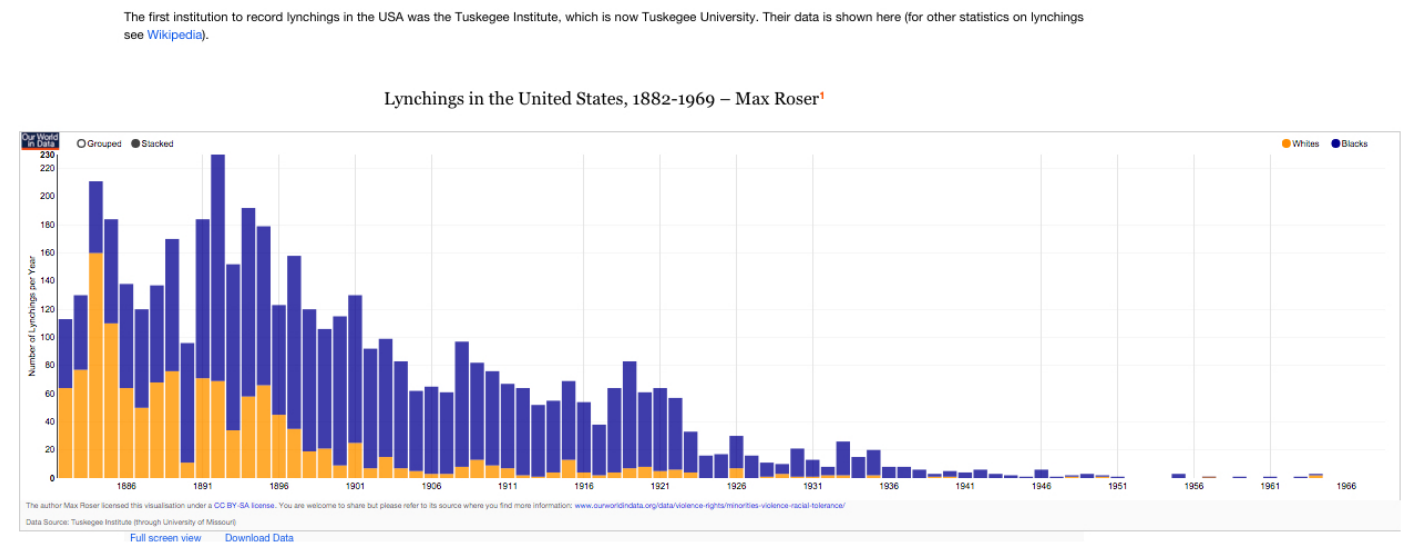

Figure 2 'Lynchings in the United States, 1882-1969 - Max Roser'. Published online at OurWorldInData.org. Note the 'Empirical View' headline.

This example is relatively easy to deconstruct (since work has been done to gather the missing data on police killings and activists have politicised this issue).

Representations of the environment are also politicised but typically it is harder to identify exactly how these hyper-complex issues are obscured in communication processes. For example, Figure 2 'Global death rate from natural catastrophes (1900-2013)' supposedly illustrates the significant improvements in humankind's capacity to survive natural catastrophes. The data here could be accurate if the approach to data collection is very narrow in its boundary conditions. Considering the ways that deteriorated environmental circumstances trigger conflict and war and the current refugee crisis - how survival is defined and measured in the wake of natural disasters must also be a contested issue. While the data could suggest that there are 
more survivors of natural catastrophes per capita in the short term, more extreme weather events are happening more often. The impact of climate de-stabilisation is already dramatic. The damage to livelihoods by extreme weather is a point of contention at yearly United Nations climate conferences. Nations on the frontline of climate impacts fiercely contest the narrative that natural catastrophes are less of a problem now than in the past (as whole island disappear under the sea).

\section{Empirical View}

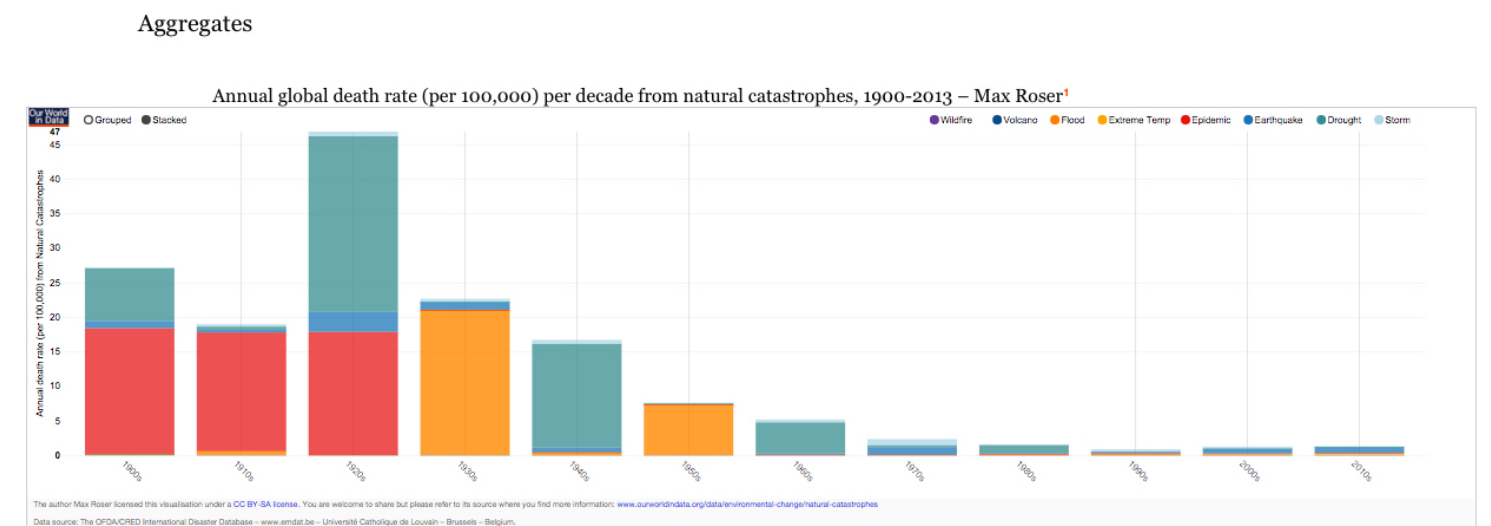

Figure 3 'Natural Catastrophes: Annual global death rate (per 100,000) per decade from natural catastrophes, 1900-1913 - Max Roser'.

These charts can be understood as datawash. Datawash is a concept that refers to data visualisation that conceals or obscures knowledge on issues of controversy. Datawash over-simplifies, cheery picks and de-contextualises information in order to present sweeping claims that obfuscate (Boehnert 2015). The associated concept of darkdata refers to the fact that what isn't measured or tracked is often as important (or more) than what is (Corby 2015). Dark data is the missing data. Where certain data is not collected this is often due to the epistemic and ideological assumptions of powerful constituencies - or simply where the communication of certain data is blatantly against their interests. For example, in the case of the charts above (figures 1 and 2), the darkdata is the dataset on police killings of black people. In cases involving the environment, darkdata can be associated with 'unintended' consequences as the implications of new technologies and development are not investigated and thus data on risks is missing.

The concepts of datawash and darkdata open discursive space by focusing attention on what is obscured, neglected and unknown. Roser presents his work as 'the empirical view' (see figure 3) but his favourite datasets are by no means the authoritative datasets. The datasets he illustrates are those that suit his particular ideological perspective. It is worth repeating: data is not neutral. It is instead an assemblage of infrastructures, laws, social discourses, technologies and politics (Corby 2015). It reflects the concerns and interpretations of social science research and the institutions that collect data. Data emerges 
"from various social concerns and practices. It is informed by history, culture, and society, and these help define, reproduce, and shape the use of this data. What interest us here are the social and organizational conventions, values, and structures that provide the 'infrastructure' through which concepts like data and information are constructed and gain legitimacy and power" (Rasanen \& Nyce 2013, p.659)

Values, sensibilities and ideologies are reflected in choices about which data is collected and selected, as well as the methods, media and styles used to communicate and use data. Decisions to use data (in a plethora of different ways) serve political priorities and agendas that must be recognised.

\section{Climaps by Emaps}

Climaps by EMAPS: A Global Issue Atlas of Climate Change Adaptation was a 3year collaborative project funded by the 7th Framework Programme of the European Union. The working group was coordinated by Sciences Po Paris. The Emaps working group published 33 issue-maps on climate change and the annual United Nations Climate Change Conference. According to the Climaps by EMAPs summary report, the project was the largest yet experiment with the method of controversy mapping:

"Controversy mapping is a research technique developed in the field of Sciences and Technology Studies (STS) to deal with the growing intricacy of sociotechnological debates. Instead of mourning such complexity, it aims to equip engaged citizens to navigate through expert disagreement. Instead of lamenting the fragmentation of society, it aims to facilitate the emergence of more heterogeneous discussion forums" (Venturini et al. 2014, p.1).

The figures below (4-8) illustrate themes in the United Nations Framework Convention on Climate Change (UNFCCC) Conference of all Parties (COP) negotiation process; top climate issues according to the Internet; and funding priorities by various donor countries. The data visualisations in this series illustrate patterns over time with visual strategies including network visualisations, flow diagrams, treemaps, scatter plots, and other (often interactive) emerging strategies.

We live in an information rich world but information alone does not necessarily lead to understanding or the capacity to act in effective ways. For example, we have an abundance of data on climate change but we have not created effective means to adapt much less mitigate impacts of a de-stabilised climate system. Data visualisation on climate change does not necessarily support effective action or politics to lower greenhouse gas emissions. Sometimes data driven methods can do more to obscure the problem than facilitate actual solutions (datawash and darkdata facilitate this process). On the other hand, communication design can and often does help audiences move from processing information to developing deeper understanding and new capacities for action. 
Knowledge visualisations aim to create deep and actionable understanding of new information. According to information theory, there is a hierarchy of four categories of communication: data, information, knowledge and wisdom:

- "Data are the pure and simple facts without any particular structure or organization, the basic atoms of information,

- Information is structured data, which adds meaning to the data and gives it context and significance,

- Knowledge is the ability to use information strategically to achieve one's objectives, and

- Wisdom is the capacity to choose objectives consistent with one's values and within a larger social context" (Logan and Stokes 2004, pp.38-39 quoted in Logan 2014, para. 35).

Communication and learning occurs at different levels. Data is reductive in that is composed of individual atomised elements. Knowledge is supported by understanding context, relationships, patterns and interdependence. Knowledge visualisation communicates trends while also supporting more integrated understanding that potentially enables agency.

In the Climaps series, the visualisations support an overview of the issues. The issue maps shift "the focus from single parts to the whole" and thereby enable "the perception of the system as an integrated structure, and understanding which properties characterise the whole system, rather than belonging to any one specific component" (Valsecchi, Ciuccarelli, Ricci and Caviglia 2010, p.2). This approach engages relational perception or ecological perception, i.e. the noticing of relations. (I use these two terms interchangeably as each has connotations I would like to emphasize).

Relational / ecological perception refers to perceptual habits and ways of seeing that emphasize relationships, context and patterns. Visual communication can be created with the explicit intention of nurturing relational perceptual practices by focusing attention on relationships. It is the focus of attention that "often means the difference between seeing and not seeing" (Sewall 1995, p.204). Through repetition we develop "visual systems structures, or neural networks, [which] determine our perceptual tendencies" (Ibid, p.207). Typically we see what we think we are looking for and what our attention trains us to see (Bateson 1972; Sewall 1995, 1999). In this way perceptual habits are culturally constructed; they are a result of perceptual habits that are encouraged within a particular culture. This understanding of the malleability of perception is significant for communication design. Since perceptual attention and perceptual habits are a basis for our way of seeing, designers have the potential to nurture changes in ways of seeing through directed selective attention (Boehnert 2012, 2014, 2017). 
RISE AND FALL OF ISSUES IN THE UNFCCC DISCUSSIONS

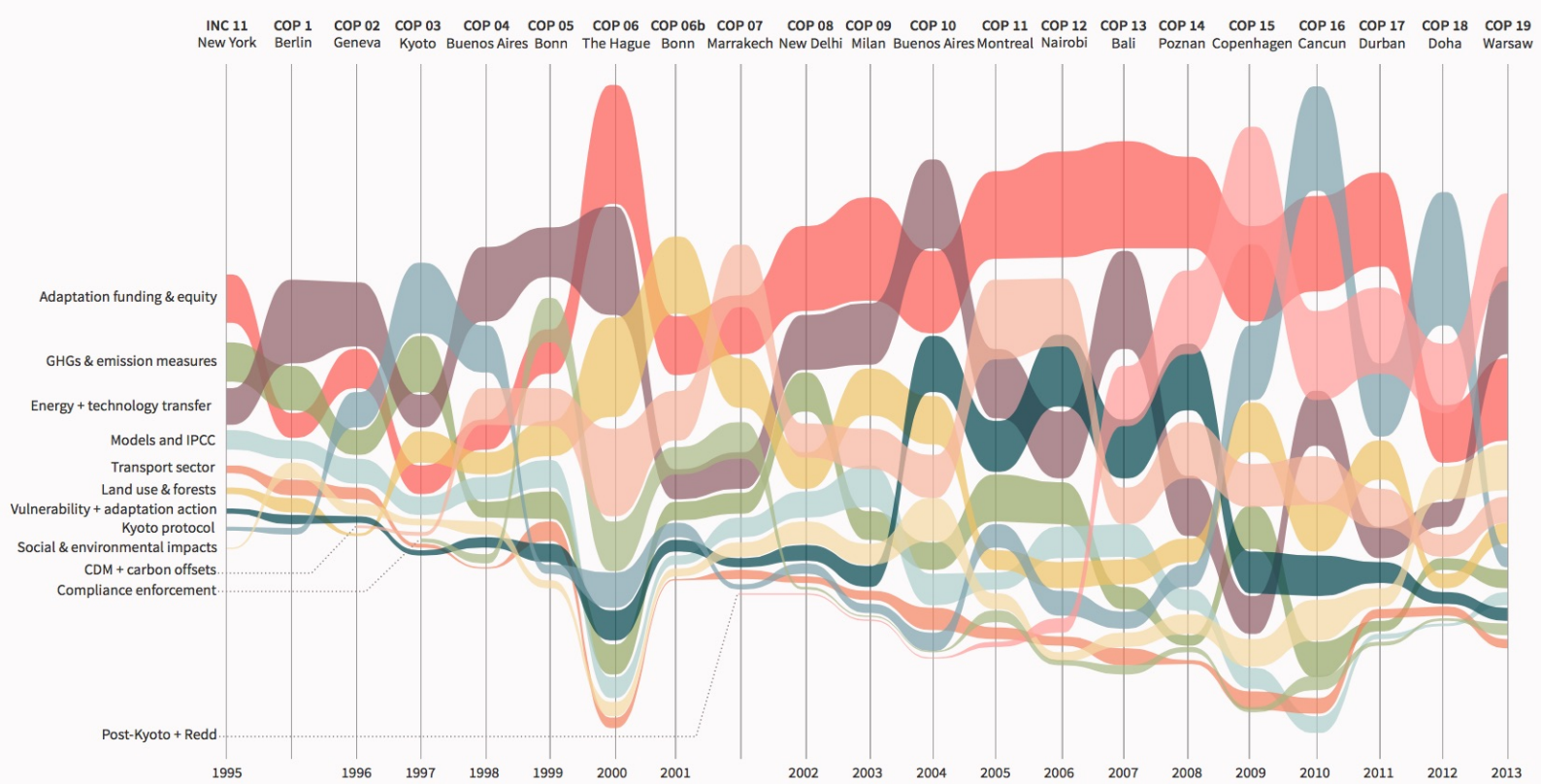

Figure 4 'Climaps by Emaps: Rise and Fall of Issues In UNFCCC Negotiations, 1995-2013'. Published online http://climaps.eu.

CHOOSE INDEX

Filter showing only the top donor country of ei $\vec{\forall}$

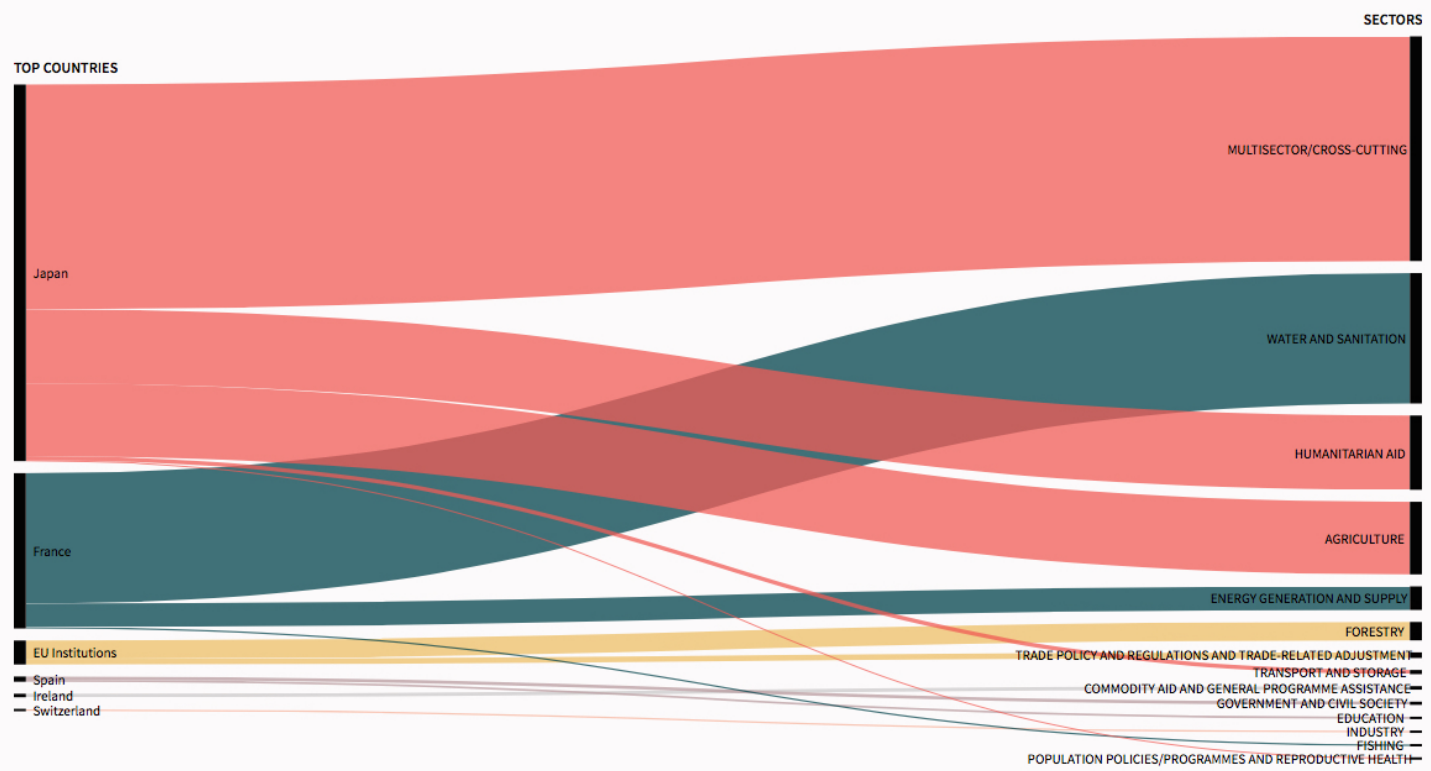

Figure 5 'Climaps by Emaps', Sectorial Specialization Of OECD Member Countries: Filter showing only top donor country of each sector. 




Figure 6 'Climaps by Emaps: Sectorial Specialization Of OECD Member Countries', Filter showing only the top area of each donor country.

The Climaps project reveals patterns and offers an overview of climate change adaptation debates. What is not evident here are the intense conflicts including outright contradictions in this highly contentious area. Within climate communication the same language is often used when referring to very different sets of interests and policy proposals. The meaning of language on politicised issues such as climate change differs according to its context. For example, the word 'sustainability' is often rendered virtually meaningless due to its use by actors who do little or nothing to reduce greenhouse gas emissions. Obfuscations in this area have serious consequences. Policy is developed based on perspectives, interpretations and ideologies. Currently policy on climate change enables industrial systems that are undermining the stability of the climate system. My own work with controversy mapping has lead me to believe that since ideologies, power relationships and contradictions are rarely if ever evident in the available datasets, controversial issues cannot be effectively communicated with data visualisation alone.
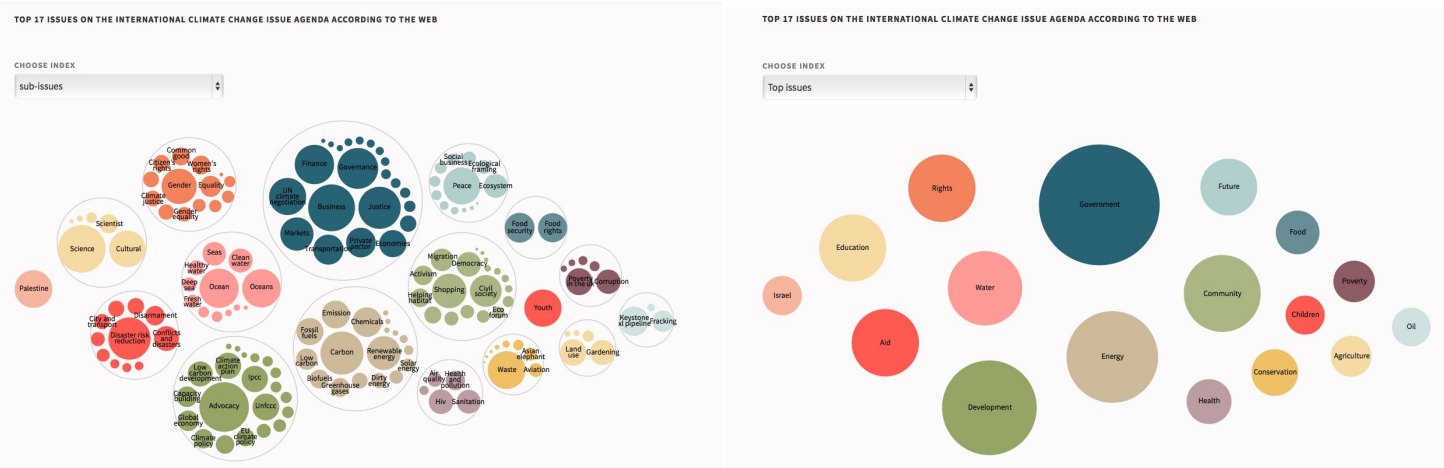

Figures 7-8 'Climaps by Emaps', top 17 sub-issues and issues on the international climate change issue agenda according to the web. 


\section{Mapping Climate Communication}

This project was created during my CIRES Visiting Fellowship at the Center for Science and Technology Policy Research at the University of Colorado Boulder. As the first communication designer to work as a researcher in the social science wing of the Cooperative Institute for Research in Environmental Sciences I was keen to demonstrate the ways in which design methods could be used to address climate communication challenges. The Mapping Climate Communication project offers an overview of how climate change is communicated in the public realm. It contextualises actors, events, strategies, media coverage and discourses influencing public opinion in ways that respond to some of the most severe climate communication challenges. I used two primary visualisation methods: a timeline and a network visualisation. The Climate Timeline visualises the historical processes and events that have lead to the growth of various ways of communicating climate change. The Network of Actors illustrates relationships between institutions, organisations and individuals participating in climate communication in Canada, United States and the United Kingdom. The large-scale knowledge visualisations and a Poster Summary Report were published on-line October 2014. The mapping process serves to investigate the issues, stimulate interest and build awareness. In this case it also serves as a conduit of theory.

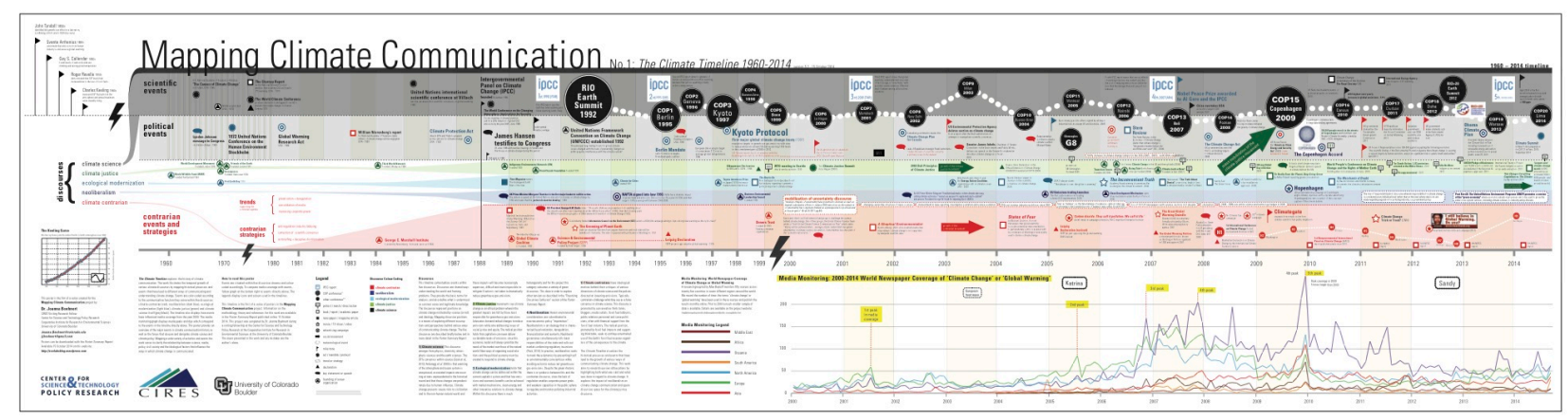

Figure 9 'Mapping Climate Communication, No. 1 The Climate Timeline', J.Boehnert, 2014

\subsection{Research Question}

My research proposal described a process that not only maps events, actors, discourses and dynamics within this area but also harnessed design as a problemsolving practice to address communication challenges. Clearly climate change is not a problem anyone can solve with a communication design research project, but designers can attempt to identity problems and address these with design methods, tools and practices. Unlike posters created to present previously conducted research, this work uses design methods to explore the research question:

How can this research facilitate collaboration, support learning, inform analysis and build capacity within the climate communication community and beyond? 




Figure 10 'Mapping Climate Communication, No. 2 Network of Actors', J.Boehnert, 2014

The problem this question addresses is obvious. Greenhouse gas emissions in North America and abroad continue to rise despite the significant work by the climate science community and the environmental movement over more than four decades. In what ways can knowledge visualisation and mapping strategies help?

I spent several months gathering data on the history of climate communication and the current major actors. This included working with Maxwell Boykoff's media monitoring group that captured data from 50 global newspapers for monthly mentions of 'climate change' over 15 years. During this time I refined my research question while investigating relevant debates, actors and strategies. After an extensive review of the literature in this area and consultations with climate communication researchers, I decided the most meaningful way to organise the information was to contextualised it as much as possible within five major discourses.

\subsection{Background and Rationale: Discourse Mapping}

Discourses are shared ways of understanding the world. They are also concepts that frame a problem. Discourses provide the basic terms for analysis and define what is understood as common sense and legitimate knowledge (Dryzek 2013, p.9). Diverse 
values, vested interests, critical perspectives and insights are embedded within discourses. These both reflect and construct attitudes towards the natural world and associated issues such as climate change. I identified five dominant climate discourses motivated by science (or not) and ideology: climate science, climate justice, climate contrarian, neoliberalism and ecological modernisation. Mapping these discursive positions illustrates similarities and differences between various ways of communicating climate change. Discourse mapping is an interpretative method that captures nuances and meaning while revealing the fluid relationships between discourses as they relate to each other and change over time.

In this project climate communication refers to all of the ways in which public understanding of climate change is developed through social communication processes. Since communication happens at the level of rhetoric as well as the level of action, discourses in this project include explicit messages on climate change and also messages that are implicit within political, corporate and non-profit organisational activities and policy. In other words it includes communication by omission, i.e. what is communicated by the denial or ignoring of climate change in places where it is relevant.

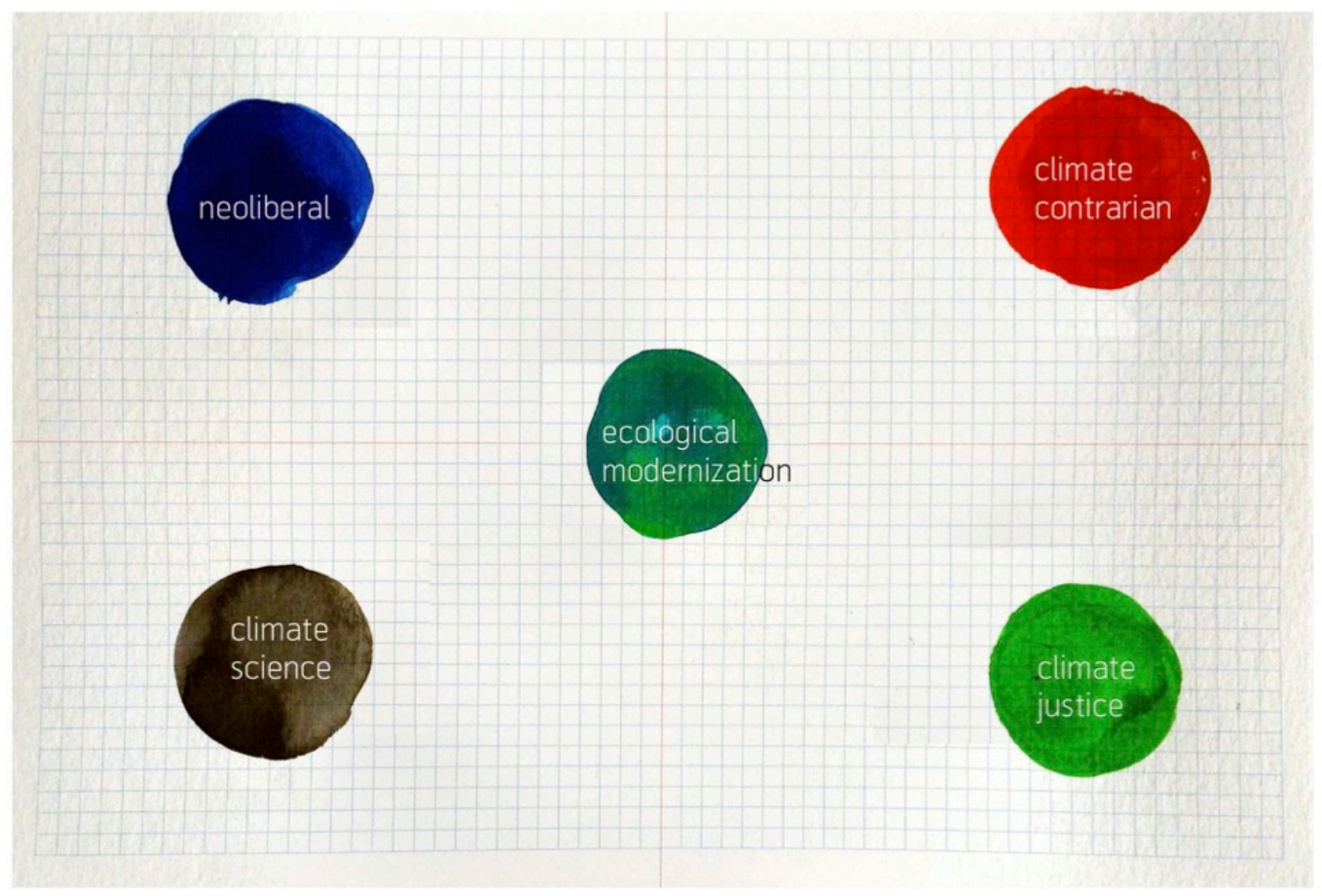

Figure 11 'Network of Actors: placement of five discourses on the matrix', J.Boehnert, 2014. 


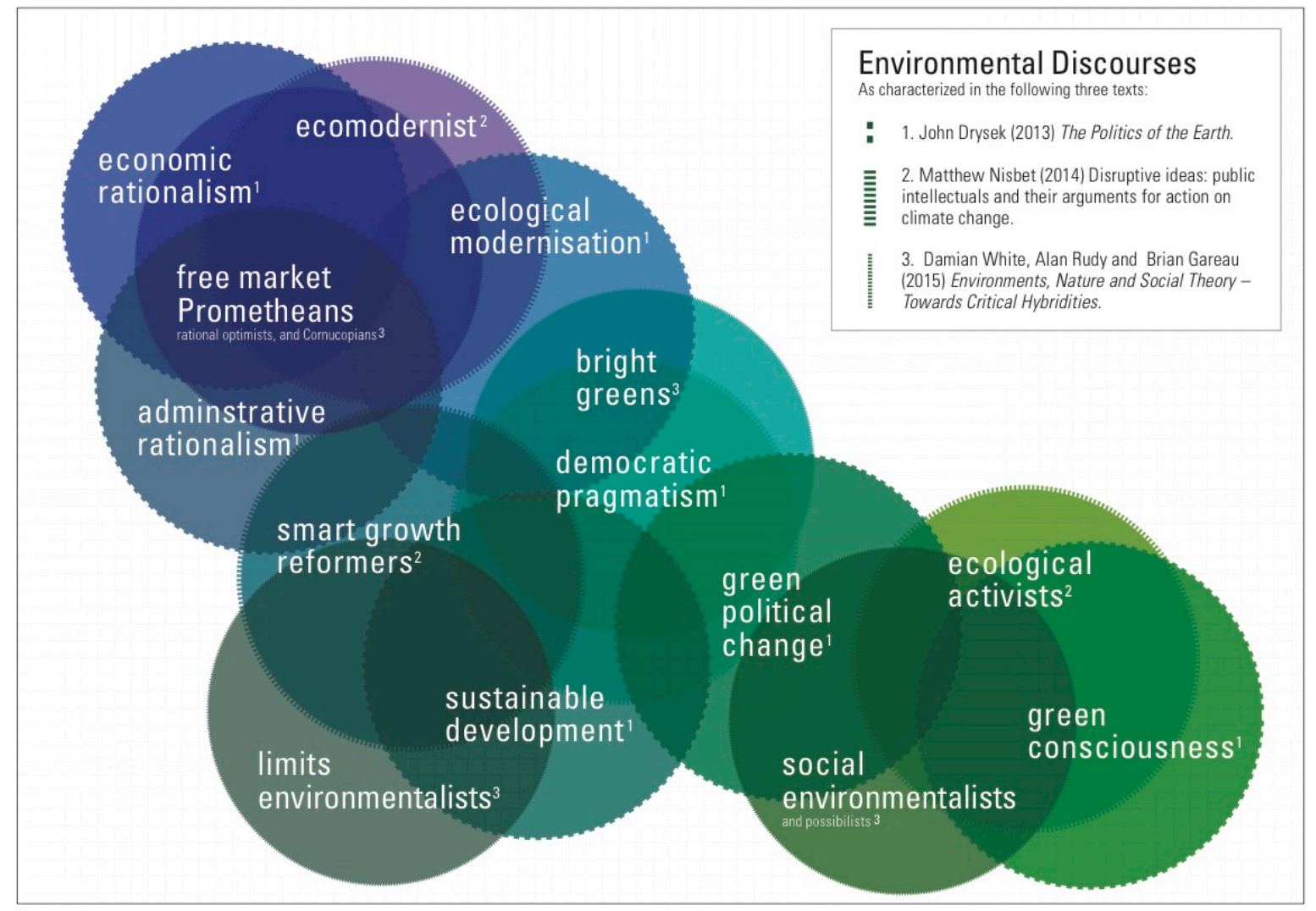

Figure 12: 'Environmental Discourses: a matrix of theories', J.Boehnert, 2014. Placement of discourses as characterised in other texts.

This approach reveals tensions in climate communication by exposing contradictions between what was said and what was done about climate change. Using this approach I developed the theory of discursive confusion and used visual strategies to illustrate it. Discursive confusion describes a situation where there are contradictions between explicit and implicit communication. Institutional actors claim that climate change is a serious threat but continue to support carbon intensive development. Following debates over four decades it is clear that obscuring rhetoric masks a lack of action. Since it is easier to say that lower emissions are necessary than to do the political work that will make this possible, this conflict between explicit and implicit messaging is important. The discursive confusion that results from contradictory communication is theorised as central to the ongoing slow progress (or according to some, a deadlock) in climate policy.

\subsection{Methodology: Systems and Discourse Mapping}

This project uses systems and discourse mapping to explore the research question. It is inspired by system oriented design (Sevaldson 2013) and visual cognitive mapping (Horn 1998; 2001; 2005). Cognitive maps are tools for communicating complex, multi-dimensional information that illustrate the "logical structure and visual structure of the emerging arguments, empirical data, scenarios, trends and policy options... and help keep the big picture from being obscured by the details" (Horn 
2001, p.5). System mapping provides an overview of the whole and make complexity accessible with strategies that capture as much meaningful information as possible while revealing hidden connections. System mapping supports relational perception by illustrating a concern with relationships:

"The systems oriented designer is initially less concerned about hierarchies and boundaries of systems and more interested in looking at vast fields of relations and patterns of interactions. She is geared towards looking at as many interrelations as possible and working with a 'field-feel' and holistic overview, while making details accessible" (Sevaldson 2013, p.3).

System maps display the structure of complex issues and reflect on issues from a wide range of perspectives. System mapping is a method well suited for environmental communication since it can reveal relationships, patterns, dynamics and causality in complex socio-ecological-political systems. In these ways system mapping enables insights across disciplines and sectors on hyper-complex issues.

In the Climate Timeline events are placed within the five discursive streams. The timeline displays how the five discourses evolve over time. Quantitative data on media mentions of climate change in over 50 global newspapers (visible in the bottom right figure 9 and figure 13) is mapped alongside events.

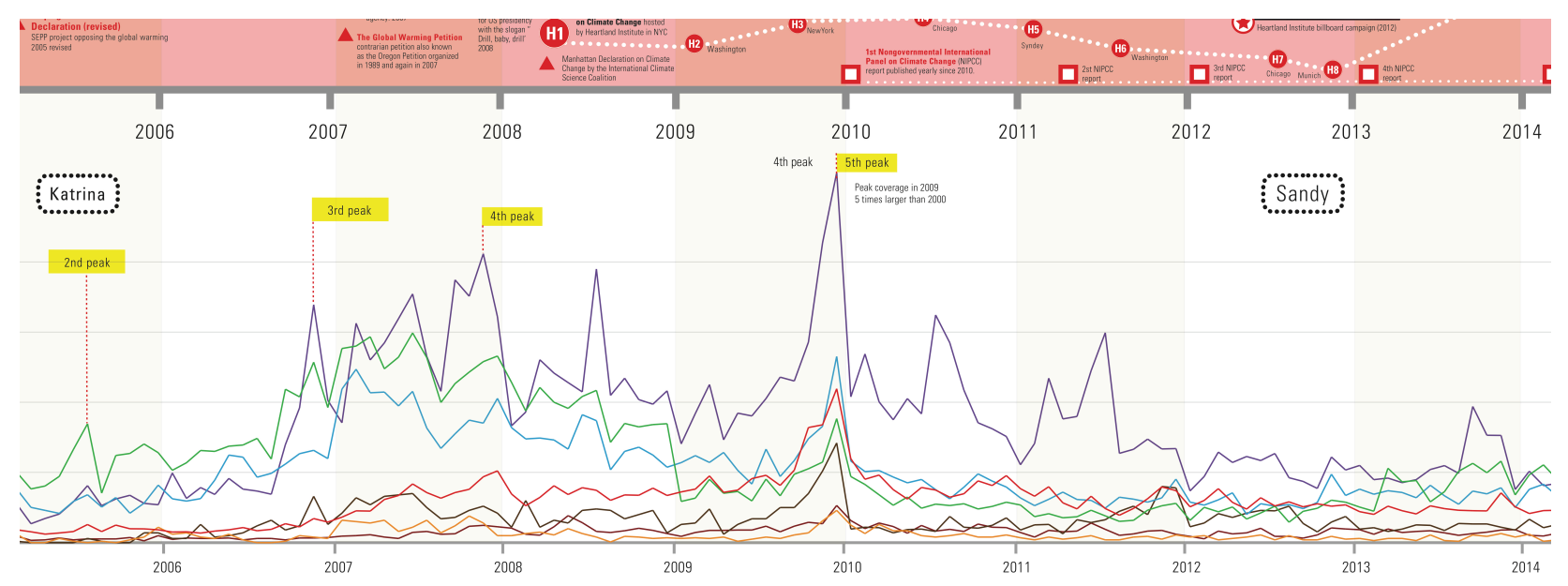

Figure 13: Detail of 'The Climate Timeline'. Media monitoring: world newspaper coverage of climate change or global warming. Monitoring 50 sources across 25 countries in 7 different regions. This detail of the line graph displays data from the seven regions (7 coloured lines) over a decade. 


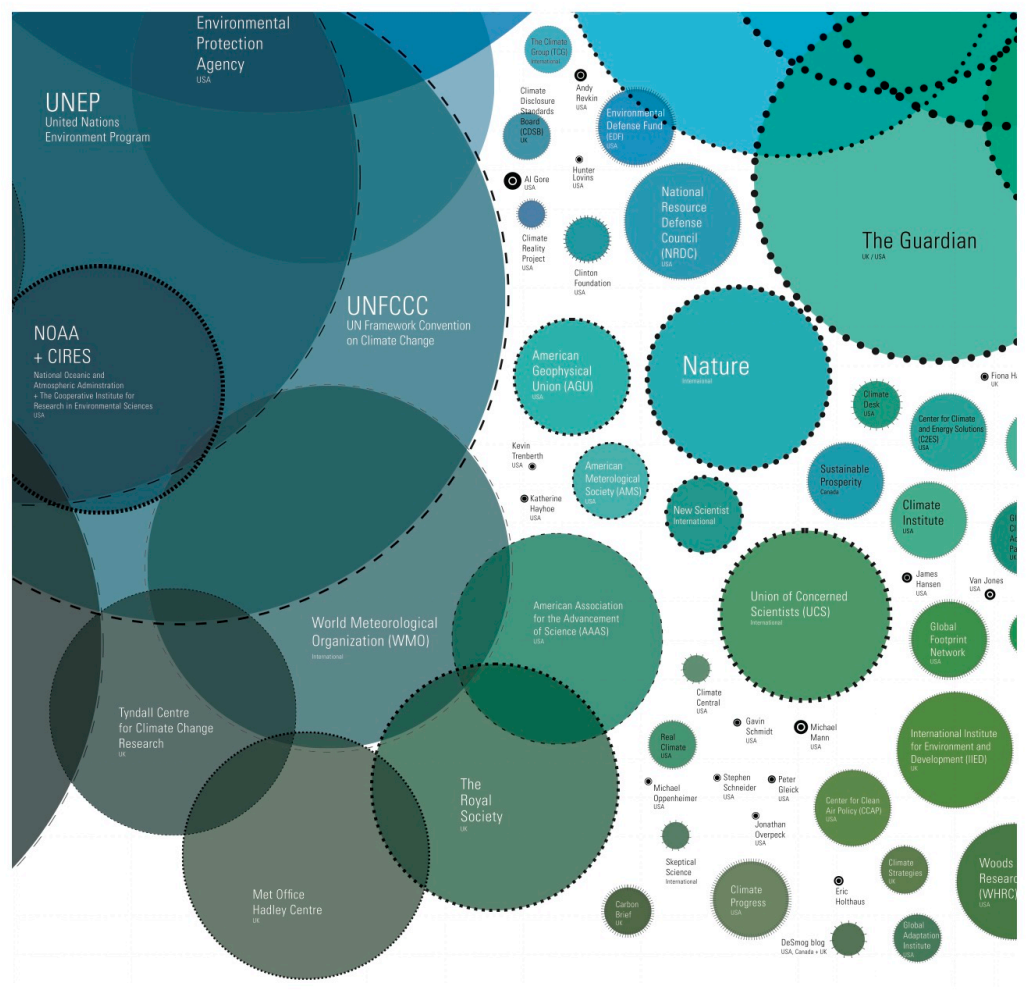

Figure 14: Detail of the 'Network of Actors'.

The accompanying Network of Actors (NoA) displays data on institutions, organisations and individuals. The actors are contextualised by their placement on the matrix (figure 11, 12 and 14). The discourse analysis and mapping is interpretation based on rhetoric, alliances and actions associated with each actor. Using visual codes the NoA also displays specific information on each actor (relative to the type: funding, audience, internet presence, etc.). In total six variables are illustrated for each actor:

1. name

2. location (Canada, USA, UK)

3. discursive position: location $\mathrm{n}$ on framework + colour

4. relative influence: size of the circle

5. type of actor: circle circumference line (see legend: figure 15)

6. Internet traffic: width of circle circumference line (see legend: figure 15)

This work displays the wide variety of actors engaged with climate communication (twelve types - see legend: figure 15) as well as the relationship of actors to each other and within a discourse map. 


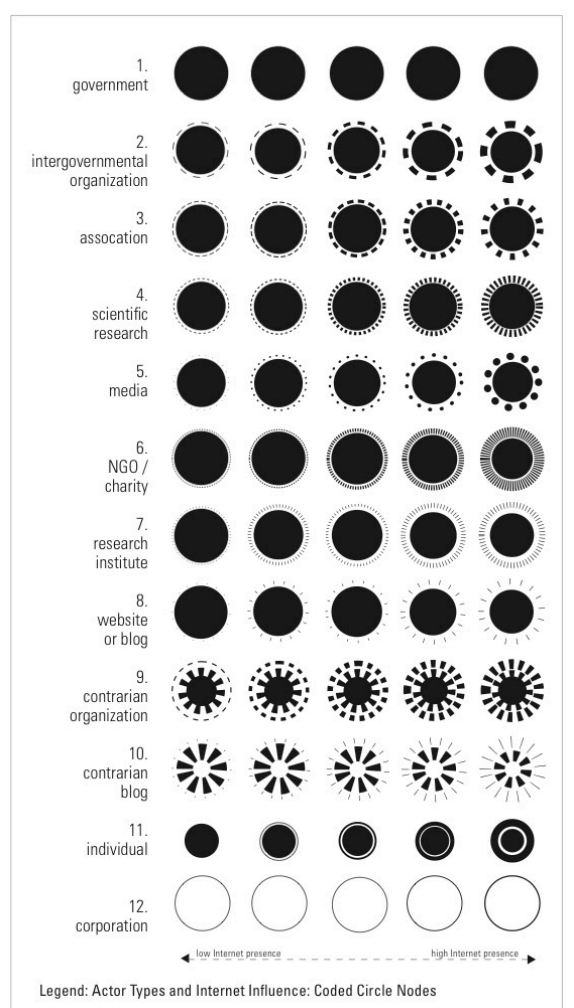

Figure 15: Detail of the 'Network of Actors'. Actor types and Internet influence: coded circle nodes. Displaying the 12 types of actors (circle style) and the Internet traffic of each actor (circle circumference width).

Placement on the matrix was a qualitative judgment based on my interpretation of the discourse emerging from this actor. This work displays the wide variety of actors engaged with climate communication; the relationship of actors to each other and within five discourses; and specific information on these actors (relative to the type of actor: funding, audience, internet presence, etc.). It also opens discursive space for the marginalised climate justice discourse by making space for these small but significant actors. I used timelines, bubble charts, network visualisations, strategies maps and other strategies in the construction of these posters. Combining quantitative comparisons and qualitative interpretations made it possible to capture power relations in this politicised area.

The method was developed after experimenting with various data-driven approaches. Overtime it became obvious that reducing the scope of the inquiry to variables that could be collected and visualised with the available datasets, by means of algorithmic network visualisation software (with accompanying reductive methods) failed to capture the complexity of ideologies and power relations significant within climate communication. A more subtle approach was necessary.

The maps explore the impact of neoliberal governance on climate communication. This analysis reveals why emissions continue to rise despite the significant work by the climate science community and the environmental movement over four decades. All three climate discourses that acknowledge the need for dramatic emissions 
reduction (climate science, climate justice and ecological modernisation) must be aware of the ways in which the neoliberal discourse appropriates their rhetorical positions. Neoliberal actors often use the language of the environmental movement to gain and maintain legitimacy and public trust. The danger here is that the climate movement's work in creating awareness and policy opinions responding to climate change is simply used as convenient rhetoric and public relations messaging for continued and even exacerbated carbon intensive development. Unfortunately, acting according to climate imperatives is difficult or even impossible within the ideological scaffolding of the neoliberal political project. With these dynamics in mind, it is evident that contrarians are not the only ones preventing action on climate change.

\section{Conclusion}

With an understanding of the malleability of perception (i.e. perceptual habits are learned and culturally constructed) and the politics of representation (i.e. certain groups have more power to create representations than others) truth-seeking visualisations must move beyond the presentation of data as the foundation for analysis. Information design guru Edward Tufte states that "excellence in presenting information requires mastering the craft of spurning ideology" $(1990,35)$ - but all communication embodies ways of knowing, perspectives and ideologies whether one is aware of our own ideological premises or not. In many cases on issues of controversy, the most relevant fact is that powerful groups are able to communicate perspectives that support their own ideological commitments and interests.

Data visualisations embody values, worldviews and ideologies that are reflected in which data is collected and selected, as well as the methods, media and styles used to communicate information. These decisions often serve political priorities and agendas. This is especially true for politically loaded issues. Critical data visualisation and information design questions what is being communicated and how it is communicated. The concepts of digital positivism, datawash and darkdata are building blocks for critical information design literacy. Obviously quantitative data displays have value - but power and ideology hide behind the presentation of data such that some interests are presented and others are obscured. Articulating the limits of data visualisation opens discursive space for more nuanced approaches such as knowledge visualisation. With this awareness designers can support knowledge transfer and avoid de-contextualised over-simplified datawash that serves a highly ideological function while appearing to deliver only the facts.

Acknowledgements: I am grateful to Maxwell Boykoff and to the Cooperative Institute for Research in Environmental Sciences for the opportunity to spend a year as a CIRES Visiting Research Fellow. I would also like to thank the AHRC for the funding my PhD at the University of Brighton and Jonathan Chapman and Julie Doyle for their support as my supervisors. 


\section{References}

Boehnert, J. (2012) The Visual Communication of Ecological Literacy: Designing, Learning and Emergent Ecological Perception. PhD thesis, Department of Design, University of Brighton.

Boehnert, J. (2014) Ecological Perception: Seeing Systems. In Proceedings of DRS 2014: Design's Big Debates, Umea, Sweden. June 16-19.

Boehnert, J. (2015) The Politics of Data Visualisation. Discover Society. 3 August 2015, 23.

Boehnert, J. (2017) Design, Ecology, Politics. London: Bloomsbury.

Bateson, G. (1972) Steps to an Ecology of Mind. Chicago: University of Chicago Press.

Brooks, D. (2013) What Data Can't do, NYTimes. 19 February 2013.

Corby, T. (2015) From un-data to 'un-visualisation, Transforming Data: Creative and Critical Directions in the Arts and Humanities. University of Westminster, 24 October 2015.

D'Ignazio, C. (2015) What would Feminist Data Visualisation Look Like? MIT Center for Civic Media, https://civic.mit.edu/feminist-data-visualization (Accessed 10 March, 2016).

Dryzek, J.S. (2013) The Politics of the Earth. 3rd edition. Oxford: Oxford University Press.

EMAPS, Electronic Maps to Assist Public Science. (2014) Climaps by Emaps: A Global Issue Atlas of Climate Change Adaptation. http://climaps.eu/\#!/home (Accesssed 15 November 2015).

Fuchs, C. (2015) A Critical Political Economy-Perspective on Big Data and Social Media, Transforming Data: Creative and Critical Directions in the Arts and Humanities. University of Westminster, 24 October 2015.

Hall, S. (1973) Encoding and Decoding in the Television Discourse. Birmingham, UK: Centre for Cultural Studies, University of Birmingham.

Horn, R. (1998) Visual Language: Global Communication for the 21st Century. Brainbridge Island: Macro VU Press.

Horn, R. (2001) Knowledge Mapping for Complex Social Messes. Foundations in the Knowledge Economy, David and Lucile Packard Foundation. July 16, 2001.

Horn, R. (2005) What we do not know: Using information murals to portray scientific ignorance. Futures, 38 (3), pp.372-377.

Logan, R. \& Stokes, L. (2004) Collaborate to Compete: Driving Profitability in the Knowledge Economy. Toronto and New York: Wiley.

Logan, R. (2014) Chapter 2: What is Information? Why Is It Relativistic and What Is Its Relationship to Materialitity, Meaning and Organization. Toronto: DEMO Publishing. http://demopublishing.com/ book/ what-is-information/chapter-2/ (Accessed 15 November 2015).

Mosco, V. (2014) To the Cloud: Big Data in a Turbulent World. Boulder: Paradigm.

Räsänen, M. and Nyce, J. (2013) 'The Raw is Cooked: Data in Intelligence Practice. Science Technology Human Vaues. 38 (5), pp. 655-677.

Roser, M. (2015) Treatment of Minorities - Violence and Tolerance. Published online at OurWorldlnData.org. Retrieved from: goo.gl/68xybg (Accessed 15 November 2015).

Roser, M. (2015) Natural Catastrophes. Published online at OurWorldInData.org. Retrieved from: goo.gl/EwlrjV (Accessed: November 15 2016).

Santos, B.S. (2007) Cognitive Justice in a Global World. Plymouth: Lexington Books.

Sevaldson, B. (2013) 'Systems Oriented Design: The emergence and development of a designerly approach to address complexity'. DRS / Cumulus Oslo 2013: 2nd International Conference for Design Research Education Researchers. Oslo, 14-17 May 2013. 
Sewall, L. (1995) The Skills of Ecological Perception. In T. Roszak, M.Gomes, and A.Kanner, (Eds.). Ecopsychology. San Francisco: Sierra Club Books, pp. 201-215.

Sewall, L. (1999) Sight and Sensibility: The Ecopsychology of Perception. New York: Putnam.

Swaine, J. \& Laughland, O. (2015) Eric Garner and Tamir Rice among those missing from FBI record of police killings. The Guardian, 15 October 2015.

http://www.theguardian.com/us-news/2015/oct/15/fbi-record-police-killings-tamir-rice-ericgarner (Accesssed 15 November 2015).

Tufte, E. (1990) Envisioning Information. Graphics Press, Cheshire: Graphics Press.

Wheatley, M. (2006) Leadership and the New Science: Discovering Order in a Chaotic World. Oakland: Berrett-Koehler Publishers.

Valsecchi, F., Ciuccarelli, P., Ricci, D. and Caviglia, G. (2010) The Density Design lab: communication design experiments among complexity and sustainability. In Proceedings Cumulus Conference 2010 Young Creators for Better City and Better Life, Shanghai, China, September 2010.

Venturini, T., Meunier, A. Munk, R. Rogers, E. Borra, B. Rieder, L. Bounegru, N. Sanchez Querubin, P. Ciuccarelli, M. Mauri, M. Azzi, D. Ciminieri, G. Uboldi, P. Gerry, H. Kitcher, R. Schon, A. Kaltenbrunner, D. Laniado, M. Fleischhauer. (2014) Climaps by EMAPS in 2 Pages (A Summary For Policymakers and Busy People in General) http://ssrn.com/abstract $=2532946$ (Accessed November 15, 2015).

About the Authors:

Dr. Joanna Boehnert is a Research Fellow in Graphic Design at CREAM, University of Westminster. She completed an AHRC funded PhD in 2012 at the University of Brighton. She is writing a book titled Design/ Ecology/ Politics and tweets as @ecolabs and @ecocene. 